\title{
PERDA DA NACIONALIDADE: UM ESTUDO DE DIREITO CONSTITUCIONAL COMPARADO DIACRÔNICO
}

\author{
Mariana Moron Saes Braga ${ }^{1}$
}

\section{Resumo:}

Em 2016, no mandado de segurança 33.864/DF, o Supremo Tribunal Federal considerou legítima a decretação, pelo Ministro da Justiça, da perda da nacionalidade de Cláudia Hoerig, uma brasileira nata. Ao denegar a segurança, um dos Ministros alegou que a perda da nacionalidade foi prevista em todas as Constituições brasileiras. A presente pesquisa pretendeu verificar se, de fato, a perda da nacionalidade foi regulada em todas as Constituições do Brasil. Posteriormente, comparar o teor dos dispositivos encontrados. Conclui-se que a perda da nacionalidade foi estabelecida em todas as Constituições e a análise evidenciou que houve poucas alterações ao longo do tempo

Palavras-chave: direito comparado; nacionalidade; naturalização; história constitucional; perda da nacionalidade

\section{LOSS OF NATIONALITY: A STUDY OF DIACHRONIC COMPARATIVE CONSTITUTIONAL LAW}

\begin{abstract}
:
In 2016, in the writ of mandamus 33.864/DF, the Brazilian Supreme Court considered legitimate the decree, by the Minister of Justice, of the loss of nationality from Cláudia Hoerig. When denying security, one of the Ministers claimed that the loss of nationality was predicted in all Brazilian Constitutions. The present research intended to verify if the loss of nationality was regulated in all Brazilian Constitutions. It intended to compare the content of the instruments found. It is concluded that the loss of nationality was established in all Constitutions and the analysis highlighted that there were few changes over time.
\end{abstract}

Keywords: comparative law; nationality; naturalization; constitutional history; loss of nationality

1- Introdução

O caso da carioca Cláudia Cristina Hoerig, a primeira pessoa a perder a nacionalidade brasileira e ser extraditada para o exterior gerou um debate sobre as

\footnotetext{
${ }^{1}$ Docente do Departamento de Sociologia e Antropologia da UNESP - Campus de Marília/SP. Coordenadora do GEMIIN - Grupo de Estudos em Migrações Internacionais Contemporâneas. Endereço eletrônico mariana.braga@unesp.br
} 
circunstâncias em que brasileiros com outras nacionalidades podem enfrentar a mesma situação.

Cláudia Cristina Sobral Alves Barbosa nasceu no Rio de Janeiro em 1964. Em 1989, migrou para os Estados Unidos e casou-se com o norte-americano Thomas Bolte. Pelo casamento, teve direito ao visto permanente, conhecido como green card.

Após dez anos do seu ingresso em território norte-americano, Cláudia se naturalizou estadunidense em 28 de setembro de 1999, adquirindo a nacionalidade daquele país. Obteve o divórcio de Thomas Bolte e, anos mais tarde, precisamente em 30 de junho de 2005, Cláudia casou novamente com um cidadão norte-americano, de nome Karl Hoerig, um condecorado Oficial da Força Aérea dos Estados Unidos².

Em 12 de março de 2007, Karl Hoerig foi assassinado em sua própria residência, em Newton Falls, Condado de Trumbull, Ohio, causando grande comoção nacional. Nesta mesma data, Cláudia voltou dos Estados Unidos para o Brasil, com o passaporte brasileiro que há muito não utilizava. As suspeitas recaíram sobre ela, inclusive tendo a promotoria local lhe denunciado perante o tribunal de júri do Condado de Trumbull.

As investigações da polícia de Ohio concluíram que Karl Hoerig havia sido alvejado por disparos de um revólver Smith \& Wesson, calibre 357, semelhante a um modelo que Cláudia havia comprado apenas cinco dias antes da descoberta do homicídio. Testemunhas disseram tê-la visto praticando tiro com a arma em um alvo próximo à casa (RAMOS, 2017).

Cláudia Hoerig alegou ser vítima de agressões físicas e abusos por parte do marido, circunstâncias que a teriam levado a cometer o crime, em momento de fúria durante uma briga conjugal. Segundo seu advogado, ela não desejava eximir-se de responder à acusação, mas que fosse no Brasil (DEL'OLMO, 2016).

Para a polícia americana, ela se converteu na suspeita número um. Um pedido de prisão foi expedido. A Interpol a incluiu na lista de procurados e o Estado americano entrou com um processo no Brasil para que ela fosse devolvida ao território americano para ser julgada.

As autoridades brasileiras instauraram o procedimento administrativo de $\mathrm{n}^{\circ}$ 08018.011847/2011-01 ao tomar conhecimento dessa acusação formal bem dos pormenores, incluindo-se o processo de naturalização de Cláudia e do pedido de extradição requerido pelo governo norte-americano através da nota verbal de $n^{\circ} 466$, ao Ministério da Justiça, de ofício.

\footnotetext{
${ }^{2}$ A partir de então passou a assinar Claudia Cristina Hoerig.
} 
A consequência deste procedimento administrativo foi justamente a edição da Portaria $\mathrm{n}^{\mathrm{o}} 2.465$, de 3 de julho de 2013 que declarou a perda da nacionalidade brasileira de Claudia Cristina Hoerig, em virtude de sua naturalização como norte-americana.

Irresignada com a decisão administrativa ministerial, Claudia impetrou mandado de segurança de $n^{\circ} 20.439$, perante o Superior Tribunal de Justiça, em que requereu a suspensão da eficácia da Portaria $n^{\circ}$ 2.465/2013 em sede liminar, bem como a revogação da aludida Portaria no mérito (DEL’OLMO, 2016).

O referido mandado de segurança tinha como argumento de fundo que a decretação da perda de sua nacionalidade brasileira seria desproporcional, uma vez que Cláudia teria se naturalizado nos Estados Unidos a fim de garantir sua permanência no território norteamericano e para exercer seus direitos civis. O Superior Tribunal de Justiça concedeu medida liminar em 4 de setembro de 2013, suspendendo, provisoriamente, a eficácia da Portaria Ministerial $\mathrm{n}^{\mathrm{o}} 2.465$, de 3 de julho de 2013, do Ministro da Justiça, até o julgamento do MS 20.439/DF pela Primeira Seção daquela Corte.

Em 10 de setembro de 2013, o Governo dos Estados Unidos da América propôs o pedido de prisão preventiva para extradição - PPE 694 - que fora distribuído ao Ministro Roberto Barroso, e cujo pedido foi indeferido pelo Supremo Tribunal Federal -STF, em 11 de setembro de 2013, em virtude da concessão pelo Superior Tribunal de Justiça da medida liminar no Mandado de Segurança no 20.439/DF24.

Em 7 de maio de 2014, a Subprocuradora-Geral da República Denise Vinci Tulio manifestou-se pela concessão da ordem no MS 20.439/DF, para que possibilitasse a manutenção da dupla nacionalidade ou que a impetrante pudesse optar pela nacionalidade brasileira ou pela norte-americana (FAVARO, 2017).

Em 17 de setembro de 2014, o Procurador-Geral da República requereu ao Superior Tribunal de Justiça, que declinasse de sua competência em favor da Corte Suprema, argumentando que o Supremo Tribunal Federal é competente para processar e julgar mandado de segurança ou habeas corpus impetrado contra ato do Ministro da Justiça, quando o objeto envolver matéria extradicional. Em 2 de julho de 2015, o Procurador-Geral da República apresentou reclamação ao Supremo Tribunal Federal em face de decisão proferida pelo STJ, no Mandado de Segurança $n^{\circ}$ 20.439/DF, por ter violado autoridade de julgados da Corte Suprema (HC 83.113/DF, HC 119.920/DF e HC 92.251/DF). 
No pedido da reclamação, o Procurador Geral da República requereu concessão de medida liminar para que os autos fossem remetidos ao STF e fosse suspensa a eficácia da decisão proferida pelo STJ no MS 20.439/DF, por ter o STJ usurpado competência da Suprema Corte para processar e julgar mandado de segurança ou habeas corpus que tenham vinculação com procedimentos de índole extradicional, o que tem obstado há quase dois anos o andamento do PPE 694, e, ao final, requereu julgamento de procedência da reclamação para determinar a cassação da decisão supramencionada e a imediata avocação do conhecimento do MS 20.439/DF para o STF (RAMOS, 2017).

Em 21 de julho de 2015, o Ministro Presidente Ricardo Lewandowski requisitou informações ao STJ sobre o MS 20.439/DF25. Por meio de decisão publicada em 23 de setembro de 2015, nos autos do MS 20.439/DF, o Ministro Relator Napoleão Nunes Maia Filho reconheceu a incompetência do STJ para apreciar o feito, revogou a liminar anteriormente concedida e determinou a remessa dos autos ao STF mantendo-se a liminar até oportuna apreciação pelo juízo competente.

A Reclamação $n^{\circ} 21.329$ foi julgada prejudicada pelo STF em 6 de novembro de 2015, tendo em vista a decisão do Ministro Napoleão Nunes Maia Filho, do STJ, que declarou a incompetência daquela Corte Superior e remeteu os autos do MS 20.439/DF ao STF, que tramitaram na Corte Suprema sob o no 33.864/DF (GOMES; ALMEIDA, 2018)

O mandado de segurança ficou sob a relatoria do Ministro Luís Roberto Barroso e foi incluído em pauta para julgamento da Primeira Turma, havendo decisão em 19 de abril de 2016.

Por maioria de votos, a Primeira Turma denegou a segurança e revogou a liminar deferida pelo Superior Tribunal de Justiça. Participaram do julgamento, o Ministro Relator, Luís Roberto Barroso, a Ministra Rosa Weber, Ministro Luiz Fux, Ministro Marco Aurélio Melo e o Ministro Edson Fachin. Os dois últimos, foram os vencidos (RAMOS, 2017).

Ao negar a ordem perseguida no mandamus impetrado por Claudia Sobral Hoerig, a Primeira Turma do Supremo Tribunal Federal, convalidou a decisão do Ministério da Justiça que declarou a perda da nacionalidade da impetrante, consubstanciada na Portaria $\mathrm{n}^{\mathbf{o}} 2.465$, revogando, assim, a liminar concedida pelo Superior Tribunal de Justiça.

A decisão do Supremo transitou em julgado em outubro de 2017. Em janeiro de 2018, Cláudia Sobral Hoerig foi extraditada para os Estados Unidos. 
Um ano após ser extraditada, Cláudia foi julgada e condenada por homicídio qualificado. A ex-brasileira foi condenada à prisão perpétua, com direito à liberdade condicional após 28 anos. O juiz Andrew Logan, ao pronunciar a sentença, e o promotor Dennis Watkins, ao propor a pena, afirmaram que estavam conformando a sentença aos parâmetros brasileiros, já que a Lei de Migração brasileira proíbe extradições para que réus sejam condenados a penas que não existem no Brasil.

O total de 28 anos é a soma de 25 anos pelo homicídio qualificado do marido de Claudia, Karl Hoerig, em 2007, e mais três anos pelo uso de arma de fogo na prática de um crime. O tempo que Cláudia esteve presa enquanto respondia ao processo, quase três anos, será descontado dos 28 anos até a concessão da liberdade condicional. Portanto, ela terá cerca de 80 anos quando puder sair da prisão ${ }^{3}$.

O Ministério da Justiça e Segurança Pública em sua página virtual confirma a informação de que a efetivação da extradição só ocorreu após os EUA terem formalmente apresentado ao Brasil o compromisso, conforme o artigo 96 da Lei $\mathrm{n}^{\circ}$ 13.445/2017, de a extraditada não ser condenada à pena de morte ou de prisão perpétua - penas possíveis segundo a legislação do Estado de Ohio, onde o crime foi cometido e julgado 4 .

Como afirmado anteriormente, o ineditismo do caso bem como sua importância tendo em vista a nacionalidade ser um direito fundamental, motivaram a realização da presente pesquisa. É a primeira vez, desde a Proclamação da República, que o governo brasileiro extradita um nacional para responder a processo em outro país.

Em âmbito constitucional, há uma questão jurídica importante pois o caso Cláudia Sobral Hoerig poderá se tornar um divisor de águas no tratamento do tema da nacionalidade brasileira.

$\mathrm{Na}$ Constituição vigente, as hipóteses para a perda da nacionalidade estão taxativamente previstas nos incisos I e II do $\square 4^{0}$ do art. 12, inadmitindo-se que venham a ser ampliadas por lei ordinária.

Conforme o disposto no Constituição, a perda da nacionalidade do brasileiro será declarada quando tiver cancelada sua naturalização por sentença judicial, em virtude de atividade nociva ao interesse nacional, ou quando o brasileiro adquirir outra nacionalidade.

\footnotetext{
${ }^{3}$ Esta notícia pode ser lida em https://www.conjur.com.br/2019-fev-10/ex-brasileira-condenada-prisao-perpetuapena-comutada. Acesso em 17/jan/2020.

${ }^{4}$ Esta informação pode ser encontrada em https://www.justica.gov.br/news/pela-primeira-vez-brasileira-queperdeu-nacionalidade-e-extraditada. Acesso em 17/jan/2020.
} 
A Emenda Constitucional de Revisão n03/94 acrescentou duas alíneas ao inciso II, $\S 4^{\circ}$ do art. 12 , contemplando situações que, uma vez verificadas, não acarretarão a perda da nacionalidade brasileira: o reconhecimento da nacionalidade estrangeira originária e a imposição de naturalização, pela norma estrangeira, como condição para permanência em seu território ou para o exercício de direitos civis ${ }^{5}$.

No caso da ex-brasileira Cláudia Hoerig, a defesa argumentou que seu caso recaía justamente na exceção contemplada na alínea $b$, uma vez que adquiriu a nacionalidade americana para poder exercer a plenitude de seus direitos civis em um país onde há enorme preconceito contra latinos, fato que jamais implicou no desejo de quebrar seus laços com o Brasil. Ainda para a defesa, nesse caso, o ato que declarou a perda de sua nacionalidade brasileira violou seu direito líquido e certo de conservar a nacionalidade brasileira.

O ponto de partida para este estudo foi uma breve manifestação de um dos Ministros do Supremo Tribunal Federal no julgamento do mandado de segurança impetrado por Claudia Hoerig.

Ao acompanhar o voto do relator, o Ministro Luiz Fux utilizou um argumento de direito comparado para fundamentar sua decisão ao afirmar que a perda da nacionalidade em razão da aquisição de outra voluntariamente foi regulada em todas as constituições anteriores.

É o que, primeiramente, pretendeu-se averiguar, se de fato a perda da nacionalidade foi regulada em todas as constituições brasileiras já existentes. Posteriormente, objetivou-se realizar um estudo de direito comparado, ou seja, comparar e analisar o teor dos dispositivos encontrados.

Conforme Silva (2009), coisas absolutamente heterogêneas não se prestam a comparação, porque esta consiste precisamente no observar o que é símile e o que é dissímil em uma mesma classe ou espécie de objetos.

Comparar significa confrontar, aproximar coisas a fim de individualizá-las e, individualizando-as, distingui-las; e, distinguindo-as, agrupá-las e classificá-las. Silva (2009)

\footnotetext{
${ }^{5}$ De acordo com o $§ 4^{\circ}$ do inciso II, do art. 12 da Constituição Federal de 1988:

Será declarada a perda da nacionalidade do brasileiro que:

I - tiver cancelada sua naturalização, por sentença judicial, em virtude de atividade nociva ao interesse nacional;

II - adquirir outra nacionalidade, salvo nos casos:

a) de reconhecimento de nacionalidade originária pela lei estrangeira;

b) de imposição de naturalização, pela norma estrangeira, ao brasileiro residente em estado estrangeiro, como condição para permanência em seu território ou para o exercício de direitos civis.

A Constituição Federal de 1988 pode ser consultada em

http://www.planalto.gov.br/ccivil_03/constituicao/constituicao.htm. Acesso em 17/01/2020
}

Revista Brasileira de História do Direito | e-ISSN: 2526-009X | Encontro Virtual | v. 6 | n. 2 | 
ressalta que muitos estudos que se qualificam como de direito comparado não o são. Segundo ele: muitas vezes se lê em monografias jurídicas um capítulo sobre o direito comparado a respeito do tema tratado. No mais das vezes não passa do uso abusivo do conceito porque, rigorosamente, não se faz, nesses casos, direito comparado, mas simples indicação da incidência do objeto da monografia ou no direito estrangeiro ou na legislação anterior.

O direito constitucional comparado pode ser estudado sob duas perspectivas, a espacial e a temporal ${ }^{6}$. Silva (2009) menciona que o método comparativo é sincrônico quando compara elementos de ordens jurídicas da mesma época, mas de lugares diferentes; assim, se se comparar o federalismo brasileiro com o da Argentina, faz-se comparação sincrônica.

A comparação jurídica é sincrônica quando se confrontam ordens jurídicas aproximadas no tempo, mas afastadas no espaço. Para ser comparação sincrônica não é necessário que os elementos a comparar sejam atuais. Podem ser comparados elementos de ordens jurídicas antigas, como seria o caso, por exemplo, de comparar as instituições da Constituição de 1924 com as da Constituição francesa de 1830.

O método comparativo é diacrônico quando compara elementos que se sucedem no tempo numa mesma comunidade. Para ser diacrônica não é necessário que a comparação se dê entre elementos sucessivos imediatos.

Podem ser comparados elementos antigos com os mais modernos, inclusive os vigentes, da mesma ordem jurídica. Assim, faz-se comparação constitucional diacrônica tanto quando se compara, por exemplo, o presidencialismo formulado pela Constituição de 1891 com o da Constituição de 1946 quanto quando se compara o federalismo formulado pela Constituição vigente com o que foi estruturado pela Constituição de $1891{ }^{7}$

Em se tratando da comparação diacrônica, Pereira (1955) esclarece que pode o investigador recuar no tempo e buscar dados informativos da instituição em sua origem, rastreando-a pelos séculos, até alcançar o momento atual.

É justamente o que pretendeu o presente estudo, comparar como a perda da nacionalidade foi formulada nas Constituições já existentes no Brasil. Nesse sentido, o intuito

\footnotetext{
${ }^{6}$ Para Silva (2009) há ainda outra perspectiva comparatista que não se encaixa em qualquer dessas duas espécies, que seria um estudo comparativo de ordens jurídicas distantes no tempo e no espaço. É um tipo de comparação que confronta uma instituição atual com suas fontes. A esse fenômeno constantinesco dá o nome de estudo comparativo diárquico, dando a esse termo uma conotação diversa, porque diárquico é adjetivo relativo a diarquia, que tem o sentido corrente de Estado governado simultaneamente por dois soberanos.

7 Alguns autores, como por exemplo, Medeiros (2010) empregam a terminologia comparação horizontal e comparação vertical para o direito constitucional comparado sincrônico e diacrônico respectivamente.
} 
foi o de investigar, comparando a concepção contemporânea da perda da nacionalidade com os seus lineamentos no passado, fixar a sua linha de evolução, permitindo então contextualizar o referido instituto no presente.

\section{2- Desenvolvimento do estudo}

Conforme já mencionado, o objetivo da presente pesquisa foi o de realizar um estudo de direito constitucional comparado diacrônico sobre a perda da nacionalidade. No Brasil, a nacionalidade emana exclusivamente do poder constituinte originário e sua aferição se dá segundo o texto constitucional vigente à época dos fatos. Como a lei fundamental está acima de todas as normas, hierarquicamente nada a ela se sobrepõe. É o poder supremo, que, na moderna proclamação do princípio democrático, pertence ao povo, como expressão da soberania nacional, fora do qual não é lícito admitir outras formas de aquisição ou perda da nacionalidade ou restringi-las.

Em sua história, o Brasil já adotou sete constituições: uma no período monárquico e seis no período republicano. Existem divergências na doutrina acerca da Emenda Constitucional $n^{\circ} 1$, de 17.10.1969 que possui defensores da ideia de que se trata de uma Constituição propriamente dita, enquanto para outros essa classificação não pode ser empregada em tal situação.

Para a presente pesquisa, a Emenda Constitucional no 1 , de 17.10.1969 foi incluída na análise por conter alterações justamente sobre a temática do direito de nacionalidade.

Dessa forma, foram consultadas e analisadas as seguintes normas constitucionais:

- Constituição Politica do Imperio do Brazil, de 25 de março de 1824

- Constituição da República dos Estados Unidos Do Brasil, de 24 de fevereiro de 1891

- Constituição da República dos Estados Unidos do Brasil, de 16 de julho de 1934

- Constituição dos Estados Unidos do Brasil, de 10 de novembro de 1937

- Constituição dos Estados Unidos do Brasil, de 18 de setembro de 1946

- Constituição da República Federativa do Brasil de 1967

- Emenda Constitucional no 1, de 17.10.1969

- Constituição da República Federativa do Brasil de 1988

O primeiro passo para atingir o objetivo proposto foi o de identificar se todas as Constituições regularam a perda da nacionalidade e em quais dispositivos. Posteriormente, 
para comparar, ou seja, identificar diferenças e semelhanças em relação à legislação analisada, foram utilizados os seguintes critérios: quantidades de hipóteses previstas para perda da nacionalidade nas Constituições, terminologia utilizada para se referir a perda da nacionalidade e análise do teor das hipóteses previstas. Os resultados são apresentados a seguir.

3- Resultados e discussões

Da leitura das Constituições existentes no Brasil foram identificados os artigos que já regularam a perda da nacionalidade. O quadro a seguir apresenta as normas constitucionais encontradas:

Quadro 01: Preceitos constitucionais que regulam a perda da nacionalidade.

\begin{tabular}{|c|c|}
\hline Constituições Brasileiras & $\begin{array}{c}\text { Preceitos } \\
\text { constitucionais }\end{array}$ \\
\hline $\begin{array}{l}\text { Constituição Politica do Imperio do Brazil (de } \\
25 \text { de março de 1824) }\end{array}$ & Art. 7. \\
\hline $\begin{array}{l}\text { Constituição da República dos Estados Unidos } \\
\text { Do Brasil (de } 24 \text { de fevereiro de 1891) }\end{array}$ & Art.71,? ? $2^{\circ}$ \\
\hline $\begin{array}{l}\text { Constituição da República dos Estados Unidos } \\
\text { do Brasil (de } 16 \text { de julho de 1934) }\end{array}$ & Art.107 \\
\hline $\begin{array}{l}\text { Constituição dos Estados Unidos do Brasil, de } \\
10 \text { de novembro de } 1937\end{array}$ & Art.116 \\
\hline $\begin{array}{l}\text { Constituição dos Estados Unidos do Brasil (de } \\
18 \text { de setembro de 1946) }\end{array}$ & Art.130 \\
\hline $\begin{array}{l}\text { Constituição da República Federativa do Brasil } \\
\text { de } 1967\end{array}$ & Art. 141 \\
\hline Emenda Constitucional $\mathrm{n}^{\circ}$ 1, de 17.10.1969) & Art.146 \\
\hline $\begin{array}{l}\text { Constituição da República Federativa do Brasil } \\
\text { de } 1988\end{array}$ & Art.12, 目 $4^{\circ}$ \\
\hline
\end{tabular}

Fonte: elaboração própria

A primeira observação a ser feita é que, logo de início, a Constituição Imperial e posteriormente, todas as demais Constituições trataram do tema da nacionalidade e consequentemente de sua perda, reservando-lhe um Capítulo ou um Título.

Apenas como curiosidade, Bernardes (1996) aponta que antes mesmo da nossa primeira Constituição e, talvez, contribuindo para influenciá-la, as Ordenações Filipinas já disciplinavam sobre a nacionalidade dos respectivos Reinos de Portugal. 
O Título LV, do Livro II do Código Filipino, definia quem eram os naturais dos Reinos de Portugal, quando tratava das pessoas que deviam ser consideradas naturais desses Reinos e dos seus Senhorios.

O Brasil, que até 1815 integrava a Monarquia e os domínios de Portugal, tinha os seus habitantes qualificados segundo a lei deste Estado. Conforme Alencar (1974), os habitantes do Brasil, uma vez satisfeitas as exigências de seus mandamentos, eram naturais do reino português, ou seja, nacionais de Portugal.

Obviamente, após a independência do Estado brasileiro, a situação que se apresenta é bem outra, e os habitantes do novo Estado soberano não mais poderiam ser considerados como naturais de Portugal. A preocupação em definir quais são os nacionais reflete bem a importância desse instituto na formação de um novo Estado (BERNARDES, 1996).

Em relação aos resultados obtidos, é possível afirmar que a maior conclusão que se pode observar da nossa história constitucional é que em termos de perda de nacionalidade nosso direito manteve-se praticamente inalterado. Esta pouca variabilidade no tempo se evidencia quando se verifica a quantidade de hipóteses previstas para a perda da nacionalidade em cada Constituição que esteve em vigor no Brasil. Conforme o quadro a seguir:

Quadro 02: Quantidade de motivos justificativos para a perda da nacionalidade previstas nas Constituições Brasileiras

\begin{tabular}{|l|c|}
\hline \multicolumn{1}{|c|}{ Constituições Brasileiras } & Número de motivos \\
\hline $\begin{array}{l}\text { Constituição Politica do Imperio do Brazil (de } \\
25 \text { de março de 1824) }\end{array}$ & 3 \\
\hline $\begin{array}{l}\text { Constituição da República dos Estados Unidos } \\
\text { Do Brasil (de 24 de fevereiro de 1891) }\end{array}$ & 3 \\
\hline $\begin{array}{l}\text { Constituição da República dos Estados Unidos } \\
\text { do Brasil (de 16 de julho de 1934) }\end{array}$ & 3 \\
\hline $\begin{array}{l}\text { Constituição dos Estados Unidos do Brasil, de } \\
10 \text { de novembro de 1937 }\end{array}$ & 3 \\
\hline $\begin{array}{l}\text { Constituição dos Estados Unidos do Brasil (de } \\
18 \text { de setembro de 1946) }\end{array}$ & 3 \\
\hline $\begin{array}{l}\text { Constituição da República Federativa do Brasil } \\
\text { de } 1967\end{array}$ & 2 \\
\hline Emenda Constitucional no 1, de 17.10.1969) & 2 \\
\hline $\begin{array}{l}\text { Constituição da República Federativa do Brasil } \\
\text { de } 1988\end{array}$ & \\
\hline
\end{tabular}

Fonte: elaboração própria. 
Além da quantidade de hipóteses, teve-se a pretensão de identificar a terminologia utilizada pelo legislador para se referir a perda da nacionalidade. A intenção foi a de verificar se foram utilizados diferentes termos podendo indicar que o sentido ao longo do tempo também tenha se modificado. É o que mostra o quadro a seguir:

Quadro 03: Terminologia utilizada para perda da nacionalidade pelo legislador constitucional.

\begin{tabular}{|l|c|}
\hline \multicolumn{1}{|c|}{ Constituições Brasileiras } & Termo utilizado \\
\hline $\begin{array}{l}\text { Constituição Politica do Imperio do Brazil (de } \\
\text { 25 de março de 1824) }\end{array}$ & $\begin{array}{c}\text { perde os direitos de } \\
\text { cidadão brasileiro }\end{array}$ \\
\hline $\begin{array}{l}\text { Constituição da República dos Estados Unidos } \\
\text { Do Brasil (de 24 de fevereiro de 1891) }\end{array}$ & $\begin{array}{c}\text { perde os direitos de } \\
\text { cidadão brasileiro }\end{array}$ \\
\hline $\begin{array}{l}\text { Constituição da República dos Estados Unidos } \\
\text { do Brasil (de 16 de julho de 1934) }\end{array}$ & perda da nacionalidade \\
\hline $\begin{array}{l}\text { Constituição dos Estados Unidos do Brasil, de } \\
10 \text { de novembro de 1937 }\end{array}$ & perda da nacionalidade \\
\hline $\begin{array}{l}\text { Constituição dos Estados Unidos do Brasil (de } \\
18 \text { de setembro de 1946) }\end{array}$ & perda da nacionalidade \\
\hline $\begin{array}{l}\text { Constituição da República Federativa do Brasil } \\
\text { de } 1967\end{array}$ & perda da nacionalidade \\
\hline Emenda Constitucional no 1, de 17.10.1969) & perda da nacionalidade \\
\hline $\begin{array}{l}\text { Constituição da República Federativa do Brasil } \\
\text { de } 1988\end{array}$ & perda da nacionalidade \\
\hline
\end{tabular}

Fonte: elaboração própria.

Como se pode perceber a primeira Carta Magna do país, a Constituição Politica do Império do Brasil, de 24 de março de 1824, utilizava o termo cidadão no sentido que hoje se emprega para nacional, na acepção jurídica, não puramente sociológica.

A Constituição da República dos Estados Unidos do Brasil, a segunda Carta Maior da nossa História e a primeira da era republicana, promulgada em 24 de fevereiro de 1891, também empregou a expressão cidadão brasileiro para identificar os indivíduos legalmente investidos na nacionalidade brasileira. Da mesma forma, não fez distinção entre nacionalidade e cidadania.

Em relação aos motivos que as legislações adotaram como justificativos para ensejar a perda da nacionalidade, de acordo com Alexandre (1956), em regra, podem ser assim agrupados: 
1- Fatos desaprovados pelo Estado expatriador, tais como a aceitação de empregos, pensões, títulos, condecorações e outros favores oferecidos por governos estrangeiros, ou a prestação do serviço militar ou juramento de fidelidade a outro país

2- Prática de certos delitos: atentados contra a independência e segurança do país, atividades políticas nocivas ao interesse nacional, abandono do país em época de calamidade ou perigo público, deserção do serviço militar ou evasão do alistamento em tempo de guerra, sentença judicial definitiva a penas perpétuas e infamantes e quebra fraudulenta.

3- Domicílio habitual e prolongado fora do país ou residência continuada no estrangeiro sem intenção de regresso

4- Unidade da nacionalidade na família: o casamento da mulher nacional com um estrangeiro ou a troca de nacionalidade do marido e o pai na vigência do matrimônio

\section{5- $\quad$ Anexação e cessão de territórios}

Considerando-se os motivos elencados anteriormente, o exame das Constituições evidencia que o Brasil se ateve somente aos dois primeiros.

A análise das constituições brasileiras permite afirmar que de $1934^{8}$ a $1967^{9}$ as três circunstâncias previstas para a perda da nacionalidade são basicamente as mesmas: naturalização voluntária em outro país, atividade nociva ao interesse nacional e aceitação de comissão, emprego ou pensão de governo estrangeiro.

O primeiro motivo encontrado na maioria das Constituições diz respeito a perda da nacionalidade por aquisição de outra, ou seja, mediante naturalização no exterior, causa relacionada ao caso Cláudia Sobral Hoerig que ensejou a realização da presente pesquisa.

Estão sujeitos a sua decretação tanto brasileiros natos, quanto naturalizados ${ }^{10}$. A referida hipótese de perda em nosso direito foi inserida em todas as Constituições incluindo a

\footnotetext{
${ }^{8}$ A Constituição de 1937 é semelhante à de 1934, não se referindo, porém, à pensão e aceitando processo adequado ao invés de processo judicial para provar a atividade nociva ao interesse nacional. Retorna, basicamente, a Constituição de 1946, aos termos da Constituição de 1934, reinserindo a pensão e exigindo sentença judicial para cancelamento de naturalização, pelo exercício de atividade nociva.

9 A Constituição de 1967 mantém os termos da Constituição de 1946, referindo-se, contudo, ao exercício de atividade contrária ao interesse nacional, como causa de cancelamento de naturalização e não atividade nociva.

${ }^{10} \mathrm{Na}$ perda da nacionalidade há que distinguir a nacionalidade originária da nacionalidade secundária. Os motivos não se aplicam, indiferentemente, às duas hipóteses. Há casos em que a perda só se verifica quando a nacionalidade não é originária.
} 
vigente, embora com redação um pouco cambiante. Por exemplo, em 1934 foi incorporado ao preceito a expressão aquisição voluntária.

Para Guimarães (1995), em relação ao requisito de voluntariedade previsto nos textos constitucionais desde 1934, a condição fundamental para que se operasse a perda da nacionalidade brasileira, em termos de naturalização voluntária, era que o brasileiro nato, efetivamente, manifestasse o seu interesse em adquirir a nova nacionalidade perante um Estado estrangeiro. Havia que restar aparente o elemento volitivo do interessado na obtenção da nova nacionalidade. Segundo o autor (1995, p.93):

Se por vontade própria, expressa ou tácita, o cidadão brasileiro adquirisse outra nacionalidade, perdia a brasileira. Em outras palavras, se a vontade fosse consultada e, em razão de manifestação expressa ou do silêncio consciente (cujo valor jurídico é configurador da voluntariedade), nova nacionalidade fosse obtida, presente se fazia a hipótese. de perda de nacionalidade brasileira. O termo constitucional "voluntária" é o que se opõe à naturalização obrigatória, imposta ou forçada.

Se o cidadão brasileiro não fosse obrigado ou forçado, por imposição atribuída de outro Estado, a ter outra nacionalidade, lícita seria, a presunção de aquisição voluntária. A exigência constitucional era da voluntariedade e não de sua forma de manifestação que assim podia ser expressa, tácita ou indireta ${ }^{11}$.

A expressão aquisição voluntária foi suprimida da atual Constituição pela emenda revisora $n^{0}$ 3/94. Segundo a nova redação, a perda da nacionalidade será decretada, como regra geral, pela simples aquisição de outra, mesmo que sem a manifestação expressa da vontade. Conforme já mencionado, exceção à regra se dá quando a naturalização decorre de imposição da norma estrangeira como condição para a permanência naquele território ou, ainda, para exercício de direitos civis no exterior.

No âmbito doutrinário, a posição majoritária é no sentido de que também na Constituição de 1988, a perda da nacionalidade brasileira está condicionada à vontade do indivíduo que se naturaliza no exterior (VELLOSO; VIEIRA, 2017).

11 Guimarães (1995) faz referência a duas situações de aquisição de outra nacionalidade, sem a perda da brasileira, segundo os textos constitucionais antigos: a primeira quando conseguida por menor de idade e a segunda quando alcançada pelo casamento, por atribuição de outro Estado, sem o concurso da vontade do naturalizando. No primeiro caso a incapacidade civil plena e, na segunda hipótese, a falta de vontade plena. 
Rezek (2008) explica que, tratando-se de naturalização voluntária no exterior, é fundamental que ocorra uma conduta ativa e específica. Do contrário, não se poderia falar em perda da nacionalidade brasileira.

Ainda que a redação tenha sofrido pequenas alterações ao longo dos textos constitucionais, o entendimento permaneceu o mesmo em relação à naturalização. Contendo ou não o termo voluntária, o entendimento era o de que o requisito básico era a voluntariedade, ou seja, quando se verifica a intenção da pessoa em obter uma nacionalidade secundária.

Em relação à prática administrativa e jurídica nas últimas décadas, Velloso e Vieira (2017) esclarecem que os decretos de perda da nacionalidade brasileira não costumam preencher muitas páginas do Diário Oficial da União (D.O.U). Há situações em que a perda da nacionalidade brasileira é exigência do Estado para o qual se requer a nacionalidade estrangeira. Isso motiva a solicitação expressa de cancelamento do interessado ao Estado brasileiro. As portarias ministeriais determinantes da perda de nacionalidade publicadas no D.O.U, em geral, decorrem deste requerimento, e não da iniciativa do Estado brasileiro.

Ainda segundo as autoras, em 2013, o Ministério da Justiça informou que instaura de ofício os procedimentos para a perda da nacionalidade brasileira ao ter notícia da naturalização voluntária. Em seguida, notifica o interessado para que conteste a medida. Haveria, ainda, certa tendência a aceitar a justificação do interessado que apresentasse documento oficial provando que a naturalização no exterior foi necessária para a fruição de direitos.

É com relativa maleabilidade que o Ministério da Justiça, nos dias atuais, tem acolhido as justificativas apresentadas por brasileiros para a naturalização voluntária. Já ocorreu, por exemplo, a manutenção da nacionalidade brasileira por se entender que há imposição da lei estrangeira sobre o indivíduo desejoso de prestar concurso público no país de adoção, desde que o edital do certame afirmasse explicitamente a exigência (VELLOSO; VIEIRA, 2017, p.14).

Coerente com o anseio do constituinte revisor, o Ministério da Justiça costuma interpretar a vontade que impulsiona a naturalização de forma favorável à continuidade dos laços com o Brasil. Assim, tem sido possível deduzir, tanto da prática administrativa como das poucas decisões jurisdicionais existentes sobre o tema, uma inclinação institucional à 
preservação da nacionalidade brasileira. A decisão recente do Supremo Tribunal Federal no caso Cláudia Hoerig pode sugerir uma possível mudança no estado de coisas.

Em relação à segunda hipótese prevista, somente os brasileiros naturalizados podem perder a nacionalidade brasileira em virtude do exercício de atividade nociva ao interesse nacional. De acordo com Rodas (1990) tal modalidade de perda não é vista com simpatia pela doutrina, pois nota-se nela uma vingança do Estado, sem vantagens práticas e com o corolário de causar aumento da apatridia.

Quadro 04: Termos utilizados para qualificar a atividade que é passível de cancelar a nacionalidade de estrangeiro naturalizado brasileiro.

\begin{tabular}{|l|c|}
\hline \multicolumn{1}{|c|}{ Constituições Brasileiras } & Termos utilizados \\
\hline $\begin{array}{l}\text { Constituição Politica do Imperio do Brazil (de 25 de } \\
\text { março de 1824) }\end{array}$ & Não previu tal hipótese \\
\hline $\begin{array}{l}\text { Constituição da República dos Estados Unidos Do Brasil } \\
\text { (de 24 de fevereiro de 1891) }\end{array}$ & Não previu tal hipótese \\
\hline $\begin{array}{l}\text { Constituição da República dos Estados Unidos do Brasil } \\
\text { (de 16 de julho de 1934) }\end{array}$ & $\begin{array}{c}\text { atividade social ou política } \\
\text { nociva ao interesse nacional }\end{array}$ \\
\hline $\begin{array}{l}\text { Constituição dos Estados Unidos do Brasil, de 10 de } \\
\text { novembro de 1937 }\end{array}$ & $\begin{array}{c}\text { atividade política ou social } \\
\text { nociva ao interesse nacional }\end{array}$ \\
\hline $\begin{array}{l}\text { Constituição dos Estados Unidos do Brasil (de 18 de } \\
\text { setembro de 1946) }\end{array}$ & $\begin{array}{c}\text { atividade nociva ao interesse } \\
\text { nacional }\end{array}$ \\
\hline Constituição da República Federativa do Brasil de 1967 & $\begin{array}{c}\text { atividade contrária ao } \\
\text { interesse nacional }\end{array}$ \\
\hline Emenda Constitucional no 1, de 17.10.1969) & $\begin{array}{c}\text { atividade contrária ao } \\
\text { interesse nacional }\end{array}$ \\
\hline Constituição da República Federativa do Brasil de 1988 & $\begin{array}{c}\text { atividade nociva ao interesse } \\
\text { nacional }\end{array}$ \\
\hline
\end{tabular}

Fonte: elaboração própria.

Guimarães (1995), destaca como razões ensejadoras da perda da nacionalidade em função de atividade nociva ao interesse nacional: a subversão por meios violentos e outras atividades atentatórias das instituições democráticas, ou as de comprovada deslealdade ao Brasil, pressuposto criminal gravíssimo que implique nocividade.

A Carta de 1934, período em que a referida hipótese de perda foi introduzida no ordenamento jurídico brasileiro, regulamentava que a declaração de cancelamento da naturalização deveria ser feita pela via judiciária, com todas as garantias de defesa, restando ao Poder Executivo a decretação da perda da nacionalidade.

Observa-se que essa restauração da necessidade de um processo judiciário ocorreu após 1946, enquanto que, nos termos da Constituição de 1937, bastava um processo adequado que se transformou em sinônimo de processo administrativo (RODAS, 1990, p. 56). 
Desse modo, a Constituição de 1946 restabeleceu o princípio da intervenção do judiciário, que havia sido consagrado inicialmente pela Constituição de 1934. Esse fato foi criticado, visto ser a naturalização ato eminentemente político, da competência discricionária do governo, que é, em outras palavras, o Poder Executivo (JABUR, 2013).

A terceira hipótese de perda prevista nos textos constitucionais de 1934 a 1967, figurou como uma espécie de perda-incompatibilidade ${ }^{12}$ : aquele que aceitasse emprego, pensão ou comissão de governo estrangeiro, sem a licença do Presidente da República, perderia a nacionalidade brasileira (BERNARDES, 1996).

Para Alexandre (1956), a perda da nacionalidade pela aceitação de emprego, pensão ou distinções oferecidas por outros Estados se justifica pela necessidade que os Estados têm de manter intacto nos cidadãos o sentimento nacional. Segundo o autor, os defensores de tal medida acreditavam que ligações estreitas com outros governos enfraqueciam, nos indivíduos, a consciência dos deveres com o próprio país.

Esta hipótese tem sido uma constante na história constitucional brasileira. A Constituição de 1924 utilizou os termos emprego, pensão ou condecoração; a de 1891, emprego ou pensão; a de 1934, pensão, emprego ou comissão. A Constituição de 1937 repete o texto da anterior e a de 1946 refere-se a comissão, emprego ou pensão. A Constituição de 1967 e a Emenda Constitucional n ${ }^{0}$ 1, de 1969 repetem a disposição da Carta de 1946.

Mesmo se o exercício da função ou a comissão do governo fossem gratuitas, desde que exercidas sem a licença do Presidente da República, acarretariam a perda da nacionalidade brasileira, exceções às Constituições de 1934 e 1937, que expressamente declaravam que se tratava de função, emprego ou comissão remunerados (BERNARDES, 1996)

Apresentadas algumas semelhanças, em relação às diferenças encontradas, também vale destacar três delas: uma em 1824, uma em 1969 e outra em 1988.

Primeiramente, a Constituição de 1824 possui uma particularidade, ou seja, prevê uma hipótese que em seguida foi abolida de todas as demais: a perda da nacionalidade em consequência de imputação de pena de banimento ${ }^{13}$.

\footnotetext{
${ }^{12}$ Para Bernardes (1996, p.206) esta espécie de perda-incompatibilidade não deixa de ser também uma espécie de perda-punição.

${ }^{13}$ Nas sociedades arcaicas, o banimento era uma das sanções mais graves, ou seja a expulsão fora do grupo, que para o expulsado leva à perda da proteção da proteção de sua coletividade deixando o sujeito entregue à própria sorte. (GILISSEN, 1995, p. 37)
} 
De acordo com Oliveira (2014), a pena de banimento é a pena que proíbe o indivíduo de permanecer em seu país de origem, perdendo o seu direito de nacionalidade.

De acordo com a Constituição de $1824^{14}$ :

Art. 7. Perde os Direitos de Cidadão Brazileiro

I. O que se naturalisar em paiz estrangeiro.

II. O que sem licença do Imperador aceitar Emprego, Pensão, ou Condecoração de qualquer Governo Estrangeiro.

III. O que for banido por Sentença.

Uma segunda diferença é encontrada na emenda constitucional de 1969 que inovou ao agregar ao seu artigo 146 um parágrafo único prescrevendo que a aquisição de nacionalidade obtida em fraude contra lei seria anulada por decreto do Presidente da República.

Ferrante (1983) distingue a situação em tela e aquela relativa ao cancelamento da naturalização por atividade contrária ao interesse nacional. Neste último caso, pressupõe-se naturalização válida que se desfaz por razões intimamente ligadas à segurança e aos interesses maiores do Estado. Naquele, a naturalização inexiste, posto que o ato que a concedeu é nulo e, como tal, sem nenhum efeito, em razão da falsidade ideológica ou material de qualquer dos documentos destinados a comprovação dos requisitos legais exigidos para a obtenção da nacionalidade. Por isso, na primeira hipótese, os efeitos da perda da nacionalidade ou ex nunc, a partir do trânsito em julgado da sentença que cancelou a naturalização enquanto, na segunda, a declaração de nulidade retroage ex tunc, alcançando a data da naturalização que por nula é como se nunca houvesse sido concedida

Por fim, uma terceira diferença. Conforme já mencionado, uma causa que sempre figurou nos textos constitucionais foi a de que aquele que aceitasse emprego, pensão ou comissão de governos estrangeiro, sem a licença do Presidente da República perderia a nacionalidade brasileira. A Constituição vigente deixou de considerar a hipótese de aceitação de cargo de governo estrangeiro, sem autorização, como fundamento para a perda da nacionalidade. Para Bastos e Martins (1989) tratava-se de hipótese bastante desatualizada com a realidade do mundo moderno, em que laços de colaboração e interdependência são cada vez mais frequentes.

\footnotetext{
${ }^{14}$ A Constituição de 1824 pode ser consultada no seguinte endereço eletrônico: http://www.planalto.gov.br/ccivil_03/Constituicao/Constituicao24.htm Acesso em 17/01/2020.
} 


\section{4- Considerações finais}

O fato de a nacionalidade ser um direito fundamental e o ineditismo do caso Cláudia Hoerig motivaram a realização da presente pesquisa. A partir de um único caso é possível pesquisar e consequentemente refletir sobre inúmeras questões. No caso em tela, um breve e simples argumento de um dos Ministros do Supremo Tribunal Federal suscitou o estudo que ora se finaliza.

Da realização da pesquisa pode-se concluir que de fato, o Ministro Luiz Fux estava correto ao afirmar que todas as Constituições já existentes no Brasil regulamentaram a perda da nacionalidade.

O que se pode depreender disso é que no Brasil sempre houve o entendimento que esse vínculo criado pela nacionalidade, entre o indivíduo e o Estado, poderia ser desfeito também pelo Estado e não somente por manifestação de vontade do titular deste direito.

Também, o que se pode perceber dos dispositivos estudados é que não ocorreram grandes alterações em relação às hipóteses que ensejariam a perda da nacionalidade contempladas na legislação. Isto quer dizer que o entendimento acerca do assunto não se modificou radicalmente, havendo regularidade ao longo do tempo.

Para concluir, pondera-se se o caso Cláudia Hoerig será um divisor de águas no tratamento do tema da nacionalidade brasileira de modo que a naturalização voluntária no exterior passe a ocasionar a ruptura do laço de nacionalidade com o Brasil. Ainda é cedo para afirmar qual a repercussão desse caso sobre a questão. Porém, há que se atentar que o caso em tela já deixou de ser o único. Na portaria $n^{\circ}$ 90, de 14 de fevereiro de 2018, o Ministro da Justiça à época decretou a perda da nacionalidade brasileira de Carlos Nataniel Wanzeler, empresário que se naturalizou norte-americano, dono da telexfree, empresa que vendia pacotes de internet e foi considerada um esquema de pirâmide financeira.

\section{Referências Bibliográficas}

ALENCAR, A. V. A. N. de. A cidadania e nacionalidade na Constituição do Império. Revista de Informação Legislativa, Brasília, p. 165-192, 1974. Trimestral.

ALEXANDRE, F. Naturalizados e outros aspectos. Rio de Janeiro: A. Coelho Branco Filho, 1956. 
BERNARDES, W. L. M. Da nacionalidade: brasileiros natos e naturalizados. Belo Horizonte: Del Rey, 1996.

BRASIL. Constituição (1824). Constituição Política do Império do Brasil. Rio de Janeiro, 22 abr. 1824. Disponível em:

<http://www.planalto.gov.br/ccivil_03/Constituicao/Constituiçao24.htm>. Acesso em: 3 jun. 2013.

Constituição (1891). Constituição da República dos Estados Unidos do Brasil. Rio de Janeiro, 24 fev. 1891. Disponível em:

<http://www.planalto.gov.br/ccivil_03/Constituicao/Constituiçao91.htm>. Acesso em: 3 jun. 2013.

Constituição (1934). Constituição da República dos Estados Unidos do Brasil. Rio de Janeiro, 16 jun. 1934. Disponível em:

<http://www.planalto.gov.br/ccivil_03/Constituicao/Constituiçao34.htm>. Acesso em: 3 jun. 2013.

Constituição (1937). Constituição da República dos Estados Unidos do Brasil. Rio de Janeiro, 10 nov. 1937. Disponível em:

<http://www.planalto.gov.br/ccivil_03/Constituicao/Constituiçao37.htm>. Acesso em: 3 jun. 2013.

Constituição (1946). Constituição da República dos Estados Unidos do Brasil. Rio de Janeiro, 18 set. 1946. Disponível em:

<http://www.planalto.gov.br/ccivil_03/Constituicao/Constituiçao46.htm>. Acesso em: 3 jun. 2013.

Constituição (1967). Constituição da República dos Estados Unidos do Brasil.

Brasília, 24 jan. 1967. Disponível em:

<http://www.planalto.gov.br/ccivil_03/Constituicao/Constituiçao67.htm>. Acesso em: 3 jun. 2013.

Constituição (1988). Constituição da República Federativa do Brasil. Brasília, 22

out. 1988. Disponível em:

<http://www.planalto.gov.br/ccivil_03/Constituicao/Constituicao.htm>. Acesso em: 3 jun. 2013.

DEL'OLMO, F. de S. Extradição de nacional no direito brasileiro: o pioneirismo do caso cláudia hoerig - doi. Revista da Faculdade de Direito da Ufmg, [S.L.], v. -, n. 69, p. 769-795, 10 fev. 2017. Revista da Faculdade de Direito da UFMG. http://dx.doi.org/10.12818/p.03042340.2016v69p769.

FAVARO, L. M. Perda da nacionalidade brasileira nata: possibilidade de extradição. Análise da decisão do STF no MS 33.864/df. In: encontro internacional do CONPEDI, 7., 2017, Braga. Anais do 7 encontro internacional do CONPEDI. Florianópolis: Conpedi, 2017. p. 156-176. 
FERRANTE, M J. Nacionalidade: brasileiros natos e naturalizados. Brasília: Editor Desconhecido, 1983. 179 p.

GILISSEN, John. Introdução histórica ao Direito. Lisboa: Fundação Calouste Gulbenkain, $1995.813 \mathrm{p}$.

GOMES, E. B.; ALMEIDA, R. S. de. Direitos Fundamentais e Extradição: a Questão da Perda da Nacionalidade Brasileira (Mandado de Segurança ${ }^{\circ}$ 33.864/DF). RDU, Porto Alegre, v. 14, n. 67, p.84-101, maio-jun, 2018.

GUIMARÃES, F. X. da S. Nacionalidade: aquisição, perda e reaquisição. Rio de Janeiro: Forense, 1995.

JABUR, J. P. V. A. Perda da nacionalidade brasileira. 2013. 72 f. TCC (monografia) - Curso de Direito, Centro Universitário de Brasília, Brasília, 2013.

MEDEIROS, O. D. de. Direito Constitucional Comparado. Breves aspectos epistemológicos. Revista de Informação Legislativa, v. 1, p. 313-332, 2010.

OLIVEIRA, M. de F. O princípio da humanidade das penas e o alcance da proibição constitucional de penas cruéis. 2014. 270 f. Dissertação (Mestrado) - Curso de Direito, Universidade de São Paulo, São Paulo, 2014.

PEREIRA, C. M. da S. Direito comparado e seu estudo. Revista da Faculdade de Direito da UFMG, Belo Horizonte, a. 7, p.35-51, out. 1955.

SILVA, J. A. da. Um pouco de direito constitucional comparado. São Paulo: Malheiros Editores, 2009.

RAMOS, L. H. P. A perda da nacionalidade por brasileiro nato: a inédita decisão do supremo tribunal federal no caso Hoerig. 2017. 46 f. TCC (Graduação) - Curso de Direito, Faculdade de Direito do Recife, Universidade Federal de Pernambuco, Recife, 2017.

REZEK, J. F. Direito internacional público: curso elementar. 11 ed. São Paulo: Saraiva, 2008.

RODAS, J. G. A nacionalidade da pessoa física. São Paulo: Revista dos Tribunais, 1990.

VELLOSO, A. F. P.; VIEIRA, J. P. Perda da nacionalidade brasileira. XII Anuário Brasileiro de Direito Internacional, Belo Horizonte, p. 11-19, 22 jan. 2017. 